\title{
PERCEPÇÃO DE STAKEHOLDERS ACERCA DA CONTRIBUIÇÃO DAS ESTRATÉGIAS AMBIENTAIS PARA A SUSTENTABILIDADE DO MUNICÍPIO E COMPETITIVIDADE DA EMPRESA: ESTUDO DE CASO EM EMPRESA DO SETOR SUCROALCOOLEIRO NO ESTADO DA PARAÍBA
}

\author{
M. F. N. BARBOSA ${ }^{1}$, G. A. CÂNDIDO e E. M. BARBOSA \\ Universidade Federal de Campina Grande (UFCG) \\ mfnbarbosa@yahoo.com.br ${ }^{1}$
}

Artigo submetido em dezembro/2012 e aceito em fevereiro/2014

\begin{abstract}
RESUMO
Este artigo faz parte de um estudo maior no qual se procurou entender como uma estratégia ambiental pode contribuir para a competitividade da empresa e para a sustentabilidade do município em que a mesma desenvolve a atividade empresarial. Para entender de forma alargada essas relações, partindo do pressuposto que os stakeholders são importantes para o sucesso da empresa no longo prazo, este artigo tem por objetivo compreender a contribuição de alguns stakeholders nas estratégias ambientais para a sustentabilidade do município e competitividade de empresa do setor sucroalcooleiro no estado da Paraíba. A pesquisa foi realizada por meio de um estudo de caso em que foram
\end{abstract}

entrevistados stakeholders que poderiam contribuir de alguma forma para entender as relações entre as variáveis da pesquisa. Constatou-se que os stakeholders percebem de forma diferenciada a contribuição da estratégia ambiental para a sustentabilidade do município e competitividade da empresa. As conclusões do estudo apontam que a interação da empresa com stakeholders que impactam em suas atividades possibilitará um fluxo de informações contínuo que poderá contribuir para uma estratégia ambiental inserida no contexto das demandas desses atores sociais com possibilidades de ganhos para o binômio competitividade/sustentabilidade.

PALAVRAS-CHAVE: Stakeholders, Estratégia Ambiental, Interação.

\section{PERCEPTION OF STAKEHOLDERS ABOUT THE CONTRIBUTION OF THE ENVIRONMENTAL STRATEGIES FOR SUSTAINABILITY OF THE CITY AND COMPETITIVENESS OF THE COMPANY: A CASE STUDY ABOUT A COMPANY IN THE SUGAR CANE INDUSTRY IN THE STATE OF PARAÍBA}

\begin{abstract}
This paper is part of a larger study where we tried to understand how an environmental strategy can contribute to the company's competitiveness and sustainability of the municipality where it develops entrepreneurial activity. To understand these relationships so extended and based on the assumption that stakeholders are important to the success of the company in the long run, it was necessary to understand the perception of some stakeholders about the contribution of environmental strategies for sustainable municipality it and competitiveness of the company sugar and ethanol industry in the state of Paraiba, which is the main objective of this article. The research was
\end{abstract}

conducted through a case study in which we interviewed stakeholders who could contribute in some way to understand and the relationships between the variables of the research. It was found that stakeholders perceive differently the contribution of environmental strategy for sustainable municipality and competitiveness. Apprehends that the company's interaction with stakeholders that impact their activities enable a continuous flow of information that could contribute to an environmental strategy into the context of the demands of these social actors with opportunities to gain the binomial competitiveness/sustainability.

KEYWORDS: Stakeholders, Environmental Strategy, Interaction. 


\section{INTRODUÇÃO}

As temáticas estratégia ambiental, sustentabilidade e competitividade, isoladas, vêm sendo estudadas por diversos autores, e observar as relações entre estas variáveis tem sido interesse de alguns pesquisadores na atualidade. (BARBOSA, 2010). Este artigo procura entender como uma estratégia ambiental pode contribuir para a competitividade de uma empresa e para a sustentabilidade do município onde desenvolve a atividade empresarial.

A sustentabilidade e a competitividade são dimensões que por muito tempo foram consideradas antagônicas em seus propósitos. Entretanto, por conta de pressões sociais, regulamentações ambientais, conscientização do consumidor, dentre outros motivos, muitas empresas têm incorporado em seu gerenciamento o conceito de sustentabilidade. As empresas estão cada vez mais conscientes que a competitividade também depende de uma política de responsabilidade com stakeholders, mais diretamente ligados à empresa no sentido de coresponsabilizarem-se pelos danos que possam estar causando ao meio ambiente.

Este artigo tem por escopo responder ao seguinte problema de pesquisa: como os stakeholders mais diretamente ligados à empresa percebem a contribuição da estratégia ambiental para a sustentabilidade do município e competitividade de empresa do setor sucroalcooleiro no estado da Paraíba.

Assim, para entender de forma alargada essas relações partindo do pressuposto que os stakeholders são importantes para o sucesso da empresa no longo prazo, este artigo tem por objetivo compreender a percepção de alguns stakeholders acerca da contribuição da estratégia ambiental para a sustentabilidade do município e competitividade de empresa do setor sucroalcooleiro no estado da Paraíba.

Este artigo encontra-se estruturado em cinco seções, incluindo a introdução. Na parte dois será exposta a fundamentação teórica, com os conteúdos: percepção ambiental; teoria dos stakeholders; estratégia ambiental; sustentabilidade e competitividade. Na parte três serão explorados os procedimentos metodológicos da pesquisa, seguida da parte quatro com os resultados e análise; na parte cinco as considerações finais são apresentadas.

\section{FUNDAMENTAÇÃO TEÓRICA}

\subsection{Percepção Ambiental}

O termo percepção tem sido definido de diversas formas, em conformidade às respectivas áreas do conhecimento que têm utilizado desse arcabouço teórico para realizar os mais diversos tipos de pesquisa. Conforme Ferreira (1999), percepção significa ato, efeito ou faculdade de perceber.

Existem várias formas de se construir a percepção. Ribeiro (2003) faz alusão à construção pelo acesso lento (mais direcionada para aquelas culturas afetas à meditação, por exemplo); existe ainda a construção pautada no raciocínio lógico (embasada na ciência); por fim, a construção voltada para o raciocínio rápido, inerente às situações de risco e os perigo 
(acontecem em momentos de muita pressão). A percepção ambiental, por sua vez, também apresenta diversos significados e diversos modos de construção.

Segundo Ferrara (1993), a percepção ambiental está diretamente ligada à lógica da linguagem com o escopo de organizar os signos expressivos dos usos e dos hábitos de um lugar. Del Rio e Oliveira (1999), em Percepção ambiental: a experiência brasileira, estruturaram uma coletânea de trabalhos sobre percepção ambiental no qual as pesquisas foram divididas em duas abordagens do conhecimento: estruturalismo e fenomenologia. A natureza teórica desses trabalhos foi subdividida em intervencionista, interpretativa e educacional.

Conforme Faggionato (2013), os indivíduos têm percepções diferentes sobre as ações no meio, sendo as respostas daí advindas produto das percepções, dos processos cognitivos, dos julgamentos e das expectativas de cada indivíduo. $O$ autor ainda acrescenta que as manifestações psicológicas, mesmo não sendo claras, são constantes e de forma inconsciente mudam a conduta das pessoas.

Tuan (1980) esclarece que embora a percepção do meio ambiente possa variar de pessoa para pessoa, bem como entre os grupos sociais, existe a possibilidade de diversas pessoas apresentarem percepções idênticas, entre outros motivos, por terem vivenciado experiências comuns. $\mathrm{O}$ autor ainda faz menção ao indivíduo nativo do ambiente e ao indivíduo visitante: enquanto o nativo se vale dos mitos e valores locais no seu processo de percepção, o visitante se pauta por elementos estéticos.

Os desdobramentos teóricos mostram a importância que a percepção ambiental assume na forma como internalizamos a questão ambiental e, a partir disto, agimos para mudar o contexto no qual estamos inseridos conforme nossos valores, experiências e aspirações.

\subsection{Teoria dos Stakeholders}

A Teoria dos Stakeholders tem sido objeto de estudo de vários pesquisadores. $\mathrm{Na}$ literatura existem os que acreditam que todos os stakeholders são importantes para a organização, como pensam Freeman (1984), Jones (1995), Donaldson e Preston (1995), Metcalfe (1998) e Moore (1999). Por outro lado, existem os estudiosos que acreditam que a importância dos stakeholders esteja diretamente atrelada a contribuição deles ao desempenho organizacional, a exemplo dos autores Atkinson e Waterhouse (1977), Shankman (1999), dentre outros.

Desde o surgimento dessa teoria, diversos modelos têm sido desenvolvidos para explicar a relação da empresa com o seu entorno, como o modelo de Freeman, considerado o pai desta teoria. Em seu modelo, Freeman afirma que a empresa estaria no centro e ligada por todos os grupos externos a ela, como fornecedores, governo, comunidade local, proprietários, clientes, empregados, concorrentes, mídia, dentre outros grupos que impactam ou são impactados pela empresa.

Outro modelo que merece destaque na literatura é o modelo stakholder salience de Mitchell, Agle e Wood (1997), que desenvolveram um modelo com três dimensões: poder, urgência e legitimidade. É considerado um modelo dinâmico pelos autores, entre outros aspectos por permitir que os gestores possam identificar de forma especial quais stakeholders realmente são importantes para a organização. Existe ainda o modelo de Whetten (1989) que adota as 
dimensões: fatores (ou variáveis, constructos, conceitos); relações entre os fatores; dinâmicas que justificam a seleção dos fatores e as relações de causalidade entre fatores e fatores temporais e contextuais que delimitam o modelo para classificar um stakeholder.

O termo stakeholder tem se delineado, de certa forma, a partir de modelos que vão se aprimorando desde o surgimento desse termo e procuram classificar os stakeholders quanto à sua importância para a empresa por meio de determinadas características, como explicitado acima. Conforme Donaldson e Preston (1995), existem uma infinidade de definições para este termo, sendo umas mais abrangentes, que consideram vários atores como importantes para a empresa e, outras menos abrangentes consideram apenas aqueles atores que impossibilitariam o funcionamento da empresa sem a sua participação como fornecedores, empregados, gerentes, proprietários, acionistas e clientes. Para os propósitos deste artigo, considera-se stakeholder todos aqueles direta ou indiretamente ligados às atividades da empresa, uma vez que entender a contribuição da estratégia ambiental para a competitividade de sistemas agroindústrias e sustentabilidade do município são dimensões complexas e vinculadas a diversos atores sociais.

\subsection{Estratégia Ambiental}

O ponto central da estratégia ambiental está em como a organização reage às mudanças que possam ocorrer em seu ambiente interno e externo. A área de abrangência das estratégias organizacionais permeia campos diferenciados e horizontes distintos; frente a esta divergência de concepções, torna-se uma tarefa árdua conceituar o termo estratégia. Assim, faz-se necessário observar o seu conceito sob o ponto de vista de alguns autores.

De acordo com Porter (1996), estratégia representa a criação de uma posição única e bem valorizada composta por um diversificado conjunto de atividades no qual o cerne do posicionamento estratégico é desenvolver atividades que a diferenciem dos concorrentes, o que significa vincular trade-offs na competição. O autor informa que o bom desempenho da estratégia envolve fazer bem muitas coisas. Assim, caso não exista acomodação entre as atividades, inexiste estratégia que diferencie a empresa da concorrência, o que compromete a sua sustentabilidade da empresa no longo prazo.

Para Key (1996), a estratégia é essencialmente incremental e adaptável, entretanto, isso não implica que a sua evolução possa ser ou não deva ser analisada, gerenciada e controlada. Conforme Henderson (1989), o processo de formação da estratégia é necessariamente racional e deliberado, uma vez que a estratégia é a procura deliberada de um plano de ação para desenvolver e harmonizar a vantagem competitiva dos negócios. O processo de formação de estratégia precisa ser profundo e amplo como forma de alcançar diversidade e unidade. (HAMEL, 1996).

Andrews (1998) define estratégia como um modelo de decisão na empresa que delimita e divulga seus objetivos, propósitos ou metas, cria a política principal e o plano para atingir as metas, e ainda demarca a extensão do negócio da empresa, o tipo de organização humana e econômica que ela é ou pretende ser, bem como a natureza da contribuição econômica e não econômica que ela pretende dar aos acionistas, empregados, consumidores e comunidade. Percebe-se pelo conceito exposto uma preocupação da empresa com stakeholders mais diretamente ligados ao negócio, mas também com a comunidade. Embora não se saiba qual a 
extensão da contribuição que se destina a esse público externo por parte da empresa, representa o início de um relacionamento que poderá se tornar uma vantagem competitiva para a mesma.

Por sua vez, Quinn (1998) propõe um conceito de estratégia iniciando por diferenciá-la de tática. Dessa forma, os elementos que irão contribuir nesta diferenciação são representados pela escala de ação, pelo nível hierárquico das decisões e pela dimensão dos seus efeitos. $O$ autor define as táticas como de curta duração, enquanto as estratégias são de longa duração, e acrescenta que a estratégia pode ser percebida tanto como uma declaração a priori com o objetivo de conduzir as ações quanto como resultado a posteriori de comportamentos de decisão atuais.

Mintzberg, Lampel e Ahlstrand (2002), por entenderem que o conceito de estratégia não é tão simples assim, propõem algumas definições que o enquadram em cinco perspectivas cunhadas como os cinco $\mathrm{P}^{\prime} \mathrm{s}^{1}$ para a estratégia. Eles sugerem estratégia como plano ou algo equivalente: direção, guia ou curso de ação para o futuro; estratégia como padrão, ou seja, constância em comportamento ao longo do tempo; estratégia como posição, que significa a localização de determinados produtos em determinados mercados; estratégia como perspectiva, o que equivale ao jeito particular como cada empresa realiza suas atividades, e estratégia como truque, ou seja, a estratégia pode se apresentar como uma manobra exclusiva para enganar um oponente ou concorrente.

A gestão ambiental abarca o planejamento e a organização, e norteia a empresa a atingir metas ambientais específicas; além do mais, representa um compromisso corporativo, podendo servir como instrumento significativo para as empresas nas suas relações com os stakeholders. (NILSON, 1998)

Assim, para os propósitos desse artigo, é mais adequado o conceito de estratégia conforme Mintzberg, Lampel e Ahlstrand (2002), por se tratar de um conceito abrangente, no qual a empresa pode escolher para o desenvolvimento de sua estratégia ambiental o enfoque mais adequado ao contexto em que está inserida. Apresentadas as considerações sobre estratégia ambiental, faz-se necessário explorar de forma abreviada a temática sustentabilidade, por ser uma das variáveis apreciadas por stakeholders em nosso estudo e que deve fazer parte da estratégia da empresa ao ser adotada em toda sua plenitude.

\subsection{Sustentabilidade}

Hardi e Zdan (1997) defendem que o progresso em direção à sustentabilidade está condicionado ao bem-estar humano e dos ecossistemas de forma equilibrada, por existir interdependência entre esses sistemas. Os autores ainda alertam que o desenvolvimento sustentável deve se apresentar de maneira qualitativa e quantitativa, diferenciando-o da ideia de crescimento econômico.

De acordo com Rutherford (1997), o grande desafio do desenvolvimento sustentável é conciliar a análise com a síntese. O autor mostra que a construção do desenvolvimento sustentável, bem como de indicadores que sirvam de medida neste processo, devem se harmonizar nas esferas macro e micro do sistema, observando-se o equilíbrio entre as dimensões econômica, ambiental e social.

\footnotetext{
${ }^{1}$ Diz respeito aos cinco significados do conceito de estratégia: plano; padrão; posição; perspectiva e truque.
} 
Para Bossel (1998), o conceito de sustentabilidade deve envolver as dimensões material, ambiental, social, ecológica, econômica, legal, cultural, política e psicológica. O autor ainda alerta que existem diversos meios para se alcançar a sustentabilidade de um sistema com resultados significativos para os envolvidos. O autor adverte que algumas sociedades se mostraram sustentáveis através de formas predatórias, que não mais se sustentam no contexto atual.

Vieira (2007), por sua vez, chama a atenção para o fato de que o conceito de desenvolvimento sustentável é sistêmico e complexo; dessa forma, para que o mesmo se concretize algumas mudanças são necessárias no seio da sociedade, a exemplo de um debate social ampliado, bem como o fortalecimento das bases de um planejamento que seja ao mesmo tempo contextual, participativo e pactuado, opondo-se então a um enfoque de pensamento reducionista que perpassa o planejamento econômico de viés tecnocrático. Assim, torna-se urgente a existência de uma visão sistêmica para a concretização das mudanças necessárias para o alcance da qualidade de vida das atuais e futuras gerações, tomando como referência os princípios do ecodesenvolvimento propostos por Ignacy Sachs (1997).

De acordo com Vasconcelos (2002), a abordagem sistêmica é instável, intersubjetiva e complexa. Quanto à instabilidade, os fenômenos devem ser considerados como processos imprevisíveis e não totalmente determináveis. Quanto à intersubjetividade, os fenômenos geralmente se relacionam em espaços consensuais. Quanto à complexidade, significa que os fenômenos são múltiplos e interativos, carecendo de contextualizações. Esse conceito está em consonância com o pensamento de Sachs (1997) quando alerta sobre algumas das condições imprescindíveis para se colocar em prática as ideias subjacentes a um novo estilo de desenvolvimento.

Capra, em seu livro $O$ ponto de mutação (1982), escreve que o recente foco da realidade pauta-se na consciência do estado de inter-relação e interdependência essencial de todos os fenômenos - físicos, biológicos, psicológicos, sociais e culturais. Dessa forma, avança sua teoria sistêmica e amplia as comunicações entre os fenômenos biológicos, naturais e sociais. Assim, ele informa que o elemento central de qualquer análise sistêmica é a noção de organização, ou "padrão de organização". Os sistemas vivos são redes autogeradoras, o que significa que o seu padrão de organização é um padrão em rede no qual cada componente contribui para a formação dos outros componentes. Essa ideia pode ser aplicada no domínio social, desde que as redes vivas sejam identificadas como redes de comunicação. O pensamento de Capra (1982) contribui para que as bases do desenvolvimento sustentável sejam internalizadas com mais nitidez, pois ao invés de enxergar apenas o fenômeno pelo prisma linear, permite uma percepção da teia de fenômenos interligados. Por outro lado, possibilita uma compreensão da existência do fenômeno da complexidade.

Ainda no sentido de contribuir para que os princípios do desenvolvimento sustentável encontrem respaldo entre as nações, vale conferir o pensamento de Leff (2002) ao constatar que a crise ambiental convoca as ciências a repensarem seus métodos e colocarem em prática metodologias que possam apreender a realidade como realmente ela se apresenta. $O$ autor propõe que a solução para os problemas ambientais e o alcance de uma racionalidade ambiental passam por mudanças significativas em relação a processos sociais capazes de promover essas mudanças, a exemplo da introdução de valores ambientais na ética individual, nos direitos humanos e na norma jurídica dos atores econômicos e sociais envolvidos nesse processo. 
As empresas, por sua vez, também podem dar contribuições para o alcance das metas do desenvolvimento sustentável. Nesse sentido, se faz necessário que exista uma liderança empresarial capaz de convencer toda a organização sobre a importância de inserir na estratégia da empresa as bases necessárias para uma cultura do desenvolvimento sustentável.

No sentido de fazer as ligações entre a empresa e o meio ambiente, Egri e Pinfield (2007) apresentam, através de uma abordagem múltipla, o ponto comum dos aspectos teóricos e práticos existentes entre as organizações e a biosfera. Assim, os autores fundamentam que é imprescindível para a contextualização teórica da ecologia e ecossistemas os seguintes aspectos: o holismo, representado pelas interconexões dentro e entre sistemas; o equilíbrio da natureza; a diversidade; os limites finitos do sistema planetário de suporte à vida e a mudança dinâmica dos processos e ciclos naturais. Apresentam duas facetas do ambientalismo: num extremo, representa a prática da teoria ecológica para uma compreensão dos sistemas sociais dentro da biosfera; noutro extremo, representa o entendimento de valores sociopolíticos humanos que seria o elo desse envolvimento das relações humanas com o ambiente natural.

Diante das argumentações expostas, é de bom termo informar que é necessária uma racionalidade econômica distinta da economia tradicional, pois esta concebe o meio ambiente apenas como um apêndice. Brown (2003) enfatiza que a economia não deve ser sobrevalorizada em detrimento das outras dimensões como a social e a ambiental, e propõe uma economia que respeite os ecossistemas dos quais depende. Em resumo, expõe que a economia deve ser apenas uma componente do Desenvolvimento Sustentável que, embora seja imprescindível, não deve sobrepor-se às outras dimensões.

\subsection{Competitividade em Sistemas Agroindustriais}

A competitividade é uma temática complexa, assim como a estratégia ambiental e a sustentabilidade. Especificamente quando se trata de uma análise competitiva de empresa pertencente a sistemas agroindustriais, as dificuldades são bem maiores. Assim, diversas metodologias e teorias tem sido desenvolvidas para se averiguar a competitividade nesses sistemas.

A metodologia de Silva e Batalha (1999) foi adaptada da proposta metodológica de Van Duren, Martin e Westgren (1991), uma vez que os mesmos consideram em suas análises aspectos intrínsecos do agronegócio. Para estes autores, a medida da competitividade pode ser obtida pela participação de mercado e pela rentabilidade de uma firma ou cadeia. Além do mais, o encontro do efeito de vários fatores redundaria dentro de um espaço de análise, dada condição de competitividade. Os fatores podem estar inseridos nos seguintes grupos de análise: fatores controláveis pela firma; fatores quase-controláveis; fatores controláveis pelo governo; fatores não controláveis.

Silva e Batalha (1999) chamam a atenção para o fato de que ações de coordenação que objetivam ampliar a competitividade da cadeia em sua totalidade fazem parte do grupo relativo aos fatores controlados pela firma e pelo Estado. Como esse cenário condiz com a realidade, 0 modelo em apreciação entende que as ações sistêmicas que alcançam a competitividade da cadeia como um todo e dos agentes formadores dessa cadeia são importantes em estudos de competitividade. 
A metodologia apresentada por Silva e Batalha (1999) adota uma postura sistêmica do produto através do Commodity Systems Approach (CSA), sendo complementada pelo modelo de gestão Supplyc Chain Management (SCM). A opção de adotar estes modelos se torna importante uma vez que o CSA está direcionado para uma visão macro do sistema, enquanto o SCM está mais voltado para os instrumentos de coordenação executados pelos atores sociais pertencentes ao sistema, quais sejam, as empresas privadas.

Farina (1999), por sua vez, traz para o debate o conceito de competitividade à luz de sistemas agroindustriais concretos e mostra os obstáculos que o conceito apresenta quanto a sua vinculação ao estabelecimento de políticas públicas direcionadas para a recuperação, permanência ou geração de vantagens competitivas desses sistemas. A autora em comento faz referência a autores como Ferraz (1995), Best (1990), Kennedy (1998) e Oster (1994) no sentido de evidenciar como a discussão sobre competitividade, estratégias empresariais e coordenação pode se complementar e se tornar adequada para o estudo da competitividade em sistemas agroindustriais. Assim, prescinde do arcabouço teórico da Economia de Custos de Transação e Organização Industrial, uma vez que essas teorias esclarecem o papel da coordenação para a efetividade (eficiência e eficácia) das estratégias competitivas para os sistemas agroindustriais.

Farina (1999) começa por mostrar que o conceito de competitividade traz implicações imediatas quando da opção por indicadores de desempenho, e firma que indicadores como custos e produtividade justificam em parte a competitividade, sendo que a inovação em produto e processo, apesar de não levar em consideração custos e produtividade, contribui para um desempenho conveniente e ainda pode contribuir decisivamente para a preservação e melhoria das participações de mercado. A autora diz que a evolução da participação no mercado representa um indicador de resultado tendo por vantagem agregar variados fatores que condicionam o desempenho, refletindo, assim, uma competitividade passada. Por sua vez, investimentos em inovação de processo e produto, recursos humanos e marketing, bem como a capacidade de açãoestratégica, vão condicionar a competitividade futura, pois estão atreladas à conservação, modificação e melhoria de vantagens competitivas dinâmicas. Farina (1999) incorpora os indicadores do seu modelo nos ambientes: organizacional, institucional, tecnológico, competitivo; nas estratégias individuais e na coordenação, sendo esta coordenação entre os atores da cadeia produtiva elemento de suma importância para o alcance de estratégias competitivas para o sistema; por extensão, as estratégias ambientais precisam estar também definidas juntamente com as estratégias competitivas nesse elo de coordenação entre os atores da cadeia produtiva.

\section{ASPECTOS METODOLÓGICOS}

A pesquisa que aqui apresentamos foi realizada por intermédio de um estudo de caso único e com método holístico, que segundo Yin (2005) é o método mais adequado quando se deseja estudar temas complexos dentro de um contexto real.

As técnicas de pesquisa utilizadas foram: pesquisa bibliográfica, exploratória, de campo e descritiva. No que tange a pesquisa de campo foram utilizados o formulário e a entrevista semiestruturada para a coleta dos dados. O tratamento dos dados realizou-se de forma qualitativa. 
Os sujeitos da pesquisa foram escolhidos de maneira não probabilista e intencional; assim, procurou-se entrevistar atores externos, mas que impactam e são impactados pelas ações da empresa, como o Poder Público do município onde a empresa desenvolvia a atividade empresarial, a Associação dos Trabalhadores Rurais do município, a Superintendência de Administração do Meio Ambiente da Paraíba (SUDEMA) e o Sindicato da Indústria de Fabricação de Álcool do Estado da Paraíba (SINDALCOOL).

Para compreender a percepção do Poder Público acerca das vaiáveis estratégia ambiental, sustentabilidade e competitividade, foram utilizados os seguintes indicadores em cada dimensão, conforme o quadro 1.

Quadro 1: Dimensões e Indicadores

\begin{tabular}{|c|c|}
\hline DIMENSÕES & INDICADORES \\
\hline ESTRATÉGIAS AMBIENTAIS & $\begin{array}{l}\text { - Importância do envolvimento da } \\
\text { empresa nas questões ambientais } \\
\text { - Cooperação entre o município e a } \\
\text { empresa no trato das questões } \\
\text { ambientais } \\
\text { - Percepções de benefícios diretos ou } \\
\text { indiretos para o município das ações de } \\
\text { gestão ambiental desenvolvidas pela } \\
\text { empresa } \\
\text { Conhecimento da estratégia ambiental } \\
\text { da Empresa }\end{array}$ \\
\hline SUSTENTABILIDADE & $\begin{array}{l}\text { - Elementos necessários à sustentabilidade } \\
\text { de um município }\end{array}$ \\
\hline COMPETITIVIDADE & $\begin{array}{l}\text { - Relações de cooperação com a } \\
\text { comunidade }\end{array}$ \\
\hline
\end{tabular}

Fonte: Elaboração dos autores (2012)

Para os propósitos deste artigo foi considerado apenas o ambiente institucional com seus respectivos indicadores para observar a percepção do Poder Público acerca da competitividade da empresa.

No que tange à SUDEMA foram feitos questionamentos acerca da conduta e performance ambientais das empresas sucroalcooleiras da Paraíba conforme indicadores da tabela 2. A entrevista com o representante do SINDALCOOL realizou-se de forma não estruturada acerca de questionamentos sobre as estratégias ambientais das empresas sucroalcooleiras do estado da Paraíba, sua competitividade e suas ações de sustentabilidade no município onde desenvolvem a atividade empresarial.

\section{ANÁLISE E DISCUSSÃO DOS RESULTADOS}

4.1 Percepção do Poder Público e da Associação dos Trabalhadores Rurais do Município que comporta a atividade empresarial em estudo

No que diz respeito à comunidade local onde está situada a empresa foram entrevistados: - Secretário de Educação do Município; a Secretária de Saúde; o Secretário de Finanças e Obras, que a época da pesquisa também despachava na Secretaria de Desenvolvimento; uma Vereadora e o Presidente dos Trabalhadores Rurais do Município. 
A Tabela 1 apresenta a percepção do poder público no que tange às Estratégias Ambientais, Sustentabilidade e Competitividade. O Poder Público foi representando por cinco agentes: Secretário da Educação, Secretário de Finanças e Desenvolvimento, Secretário da Saúde, um representante do Poder Legislativo (vereador) e um Presidente de uma Associação.

Tabela 1 - Análise da percepção do poder público acerca das ações da empresa em relação às práticas ambientais, sustentabilidade e competitividade segundo os agentes pesquisados

\begin{tabular}{c|c|c|c|c|c|c|}
\hline \multirow{2}{*}{ DIMENSÕES } & \multicolumn{3}{|c|}{ AGENTES } & \multicolumn{2}{c}{ TO- } \\
\cline { 2 - 5 } & $\begin{array}{c}\text { SEC } \\
\text { EDU }\end{array}$ & $\begin{array}{c}\text { SEC } \\
\text { FIN } \\
\text { (1) }\end{array}$ & $\begin{array}{c}\text { SEC } \\
\text { SAL } \\
\text { (3) }\end{array}$ & $\begin{array}{c}\text { VER } \\
\text { (4) }\end{array}$ & $\begin{array}{c}\text { PRE } \\
\text { ASS } \\
(5)\end{array}$ & $\begin{array}{c}\text { TAL } \\
\text { (\%) }\end{array}$ \\
\hline
\end{tabular}

\section{ESTRATÉGIAS AMBIENTAIS}

VISÃO DO MUNICÍPIO SOBRE GESTÃO AMBIENTAL DA EMPRESA

1. Importância do envolvimento da Empresa nas questões ambientais.

2. Forma de cooperação entre o município e a empresa no trato das questões ambientais.

3. Percepções de benefícios diretos ou indiretos para o município das ações de gestão ambiental desenvolvidas pela empresa.

4. Conhecimento da estratégia ambiental da Empresa

TOTAL DE ACERTOS (\%)

\section{COMPETITIVIDADE}

RELAÇÕES DE COOPERAÇÃO COM A COMUNIDADE

Percepção sobre a comunidade em relação a:

Nível de confiança

$\begin{array}{cccccc}\checkmark & \checkmark & \checkmark & \checkmark & \checkmark & 5 \\ \checkmark & \checkmark & \times & \checkmark & \checkmark & 4 \\ \checkmark & \checkmark & \checkmark & \checkmark & \checkmark & 5 \\ & & & & & 100 \%\end{array}$

Percepção em relação ao comportamento e ações da comunidade

As relações entre as pessoas são geralmente harmoniosas

$\begin{array}{lllllc}\checkmark & \checkmark & \checkmark & \checkmark & \checkmark & 5 \\ 100 \%\end{array}$

As pessoas visam apenas seu próprio bem estar

A maioria das pessoas são honestas e confiáveis

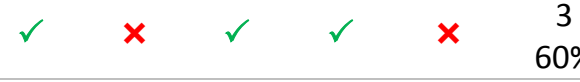

As pessoas contribuem (tempo e dinheiro) $p$ / desenvolv.

Existência de ações coletivas visando melhoria dos serviços públicos

\begin{tabular}{cccccc}
$\checkmark$ & $\checkmark$ & $\checkmark$ & $\checkmark$ & $\checkmark$ & 5 \\
$\checkmark$ & $\times$ & $\checkmark$ & $\times$ & $\checkmark$ & 3 \\
$\times$ & $\times$ & $\times$ & $\times$ & $\checkmark$ & $100 \%$ \\
$\times$ & $\times$ & $\times$ & $\times$ & $\checkmark$ & 1 \\
2 & 1 & 2 & 1 & 4 & $10 \%$ \\
$50 \%$ & $25 \%$ & $50 \%$ & $25 \%$ & $100 \%$ & $50 \%$ \\
\hline
\end{tabular}

Interesse e espírito de participação

$\begin{array}{llllll}\checkmark & \checkmark & \checkmark & \times & \checkmark & 4 \\ & & & & 80 \%\end{array}$

$\checkmark \quad \checkmark \quad \checkmark \quad \times \quad \checkmark \quad 4$

fluência da empresa para melhoria da comunidade

\begin{tabular}{|c|c|c|c|c|c|c|}
\hline A empresa está ligada a algum programa socioambiental & $\checkmark$ & $\mathbf{x}$ & $x$ & $x$ & $\checkmark$ & $\begin{array}{c}2 \\
40 \%\end{array}$ \\
\hline Existe alguma influência no governo local & $\checkmark$ & $x$ & $x$ & $\mathbf{x}$ & $x$ & $\begin{array}{c}1 \\
20 \%\end{array}$ \\
\hline $\begin{array}{l}\text { Exerce influência e pode contribuir para melhorar a vida das } \\
\text { pessoas na comunidade }\end{array}$ & $\checkmark$ & $\checkmark$ & $\checkmark$ & $\checkmark$ & $\checkmark$ & $\begin{array}{c}5 \\
100 \%\end{array}$ \\
\hline E ACERTOS (\%) & $\begin{array}{c}11 \\
100 \%\end{array}$ & $\begin{array}{c}7 \\
64 \%\end{array}$ & $\begin{array}{c}8 \\
73 \%\end{array}$ & $\begin{array}{c}7 \\
64 \%\end{array}$ & $\begin{array}{c}8 \\
73 \%\end{array}$ & $\begin{array}{c}41 \\
75 \%\end{array}$ \\
\hline
\end{tabular}




\section{AVALIAÇÃO DA CONTRIBUIÇÃO DO SETOR SUCROALCOOLEIRO PARA O DESENVOLVIMENTO DO MUNICÍPIO}

Avaliação da contribuição do setor para o município

Fonte: Pesquisa Direta (2009).

(1) SEC EDU - Secretário de Educação

(2) SEC FIN - Secretário de Finanças

(3) SEC SAU - Secretário de Saúde

(4) VER - Vereador

(5) PRE ASS - Presidente de Associação

Os indicadores utilizados na percepção das Estratégias Ambientais da Empresa Base pelo Município foram: importância do envolvimento da empresa nas questões ambientais; forma de cooperação entre o município e a empresa no trato das questões ambientais; percepções de benefícios diretos ou indiretos para o município das ações de gestão ambiental desenvolvidas pela empresa e conhecimento da estratégia ambiental da Empresa.

Numa primeira abordagem, comparando-se os índices de respostas positivas entre os agentes, percebe-se que as Estratégias Ambientais atingiram um índice de 50\%, ou seja, das 20 (vinte) respostas que compuseram esta variável, 10 (dez) deles foram avaliados positivamente. Entre os agentes entrevistados observa-se um comportamento adverso: O Presidente da Associação avaliou positivamente todos os quatro itens considerados nas Estratégias Ambientais, enquanto os Secretários de Educação e de Saúde atingiram um índice de $50 \%$ de respostas positivas e de $50 \%$ de respostas negativas para os mesmos indicadores. Os outros agentes (Secretário das Finanças e Vereador) alcançaram índices pouco expressivos, apenas $25 \%$.

Por outro lado, analisando as variáveis das Estratégias Ambientais, observa-se que uma delas, a "Importância do envolvimento da empresa nas questões ambientais", foi destacada positivamente por todos os agentes enquanto que outras duas (Percepções de benefícios diretos ou indiretos para o município das ações de gestão ambiental desenvolvidas pela empresa e Conhecimento da estratégia ambiental da Empresa) foram avaliadas positivamente apenas pelo Presidente da Associação dos Trabalhadores Rurais do Município.

O Quadro 2 apresenta os resultados das ações que os entrevistados apontaram que a Empresa Base (empresa do estudo de caso) deveria desenvolver para minimizar os impactos ambientais negativos no município.

Quadro 2: Ações que poderão ser realizadas pela Empresa no Município

\begin{tabular}{|c|c|c|c|c|}
\hline $\begin{array}{l}\text { Secretaria de } \\
\text { Educação }\end{array}$ & $\begin{array}{c}\text { Secretaria de Finanças } \\
\text { e Desenvolvimento }\end{array}$ & $\begin{array}{l}\text { Secretaria de } \\
\text { Saúde }\end{array}$ & Vereador & $\begin{array}{l}\text { Presidente da } \\
\text { Associação dos } \\
\text { Trabalhadores }\end{array}$ \\
\hline $\begin{array}{l}\text { A primeira ação } \\
\text { seria o } \\
\text { compromisso com } \\
\text { os trabalhadores; a } \\
\text { segunda seria a } \\
\text { recuperação das } \\
\text { matas ciliares; a } \\
\text { terceira o fim das } \\
\text { queimadas e a } \\
\text { última o uso dos } \\
\text { agrotóxicos. }\end{array}$ & $\begin{array}{l}\text { Educação Ambiental } \\
\text { (população do entorno } \\
\text { e funcionários); solo } \\
\text { (correção); rodízio de } \\
\text { culturas (parceria); } \\
\text { preservação } \\
\text { nascestes; } \\
\text { reflorestamento de } \\
\text { margens. }\end{array}$ & $\begin{array}{l}\text { Uso os } \\
\text { equipamentos } \\
\text { (manutenção); } \\
\text { treinamento de } \\
\text { funcionários; } \\
\text { prevenção dos } \\
\text { trabalhadores; } \\
\text { destino adequado } \\
\text { dos resíduos. }\end{array}$ & Fiscalização & $\begin{array}{l}\text { Mutirão; deixar a } \\
\text { distância da água } \\
\text { para a planta no } \\
\text { rio. }\end{array}$ \\
\hline
\end{tabular}


Fonte: Pesquisa de Campo (2009)

A percepção das ações de sustentabilidade da Empresa Base pelos atores locais foi averiguada pelo seguinte indicador: elementos necessários à empresa para contribuir com a sustentabilidade de um município. As respostas estão representadas no Quadro 3.

Quadro 3: Percepção das ações de sustentabilidade da Empresa Base pelos atores locais

\begin{tabular}{|c|c|c|c|c|}
\hline $\begin{array}{l}\text { Secretaria de } \\
\text { Educação }\end{array}$ & $\begin{array}{c}\text { Secretaria de } \\
\text { Finanças e } \\
\text { Desenvolvimento }\end{array}$ & Secretaria de Saúde & Vereadora & $\begin{array}{c}\text { Presidente da } \\
\text { Associação dos } \\
\text { Trabalhadores }\end{array}$ \\
\hline $\begin{array}{l}\text { Alfabetização dos } \\
\text { funcionários; apoio à } \\
\text { Cultura; I } \\
\text { investimento na } \\
\text { identidade do } \\
\text { município; } \\
\text { recuperação dos } \\
\text { grupos culturais; as } \\
\text { empresas privadas } \\
\text { têm } \\
\text { responsabilidades } \\
\text { pelo } \\
\text { desenvolvimento do } \\
\text { município. }\end{array}$ & $\begin{array}{l}\text { Atividades } \\
\text { renováveis; } \\
\text { preocupação com } \\
\text { os interesses da } \\
\text { comunidade; } \\
\text { projetos: educação; } \\
\text { culturais; proteção } \\
\text { ambiental. }\end{array}$ & $\begin{array}{l}\text { Ampliar emprego } \\
\text { para pessoas do } \\
\text { município gera } \\
\text { qualidade de vida. }\end{array}$ & $\begin{array}{l}\text { Fortalecimento } \\
\text { da empresa }\end{array}$ & $\begin{array}{l}\text { Trabalhar só com } \\
2 \% \text { de máquinas; } \\
\text { deixar } 80 \% \text { para os } \\
\text { trabalhadores. }\end{array}$ \\
\hline
\end{tabular}

Fonte: Pesquisa de Campo, 2009.

Pelos resultados, percebe-se a divergência de opiniões entre os atores do município em relação aos elementos necessários à empresa no sentido de contribuir com a sustentabilidade do município.

A Secretaria de Educação reconhece que as empresas privadas têm responsabilidades com o desenvolvimento do município e chama a atenção para a variável cultural como uma dimensão que carece ser mais bem apreciada no município pela empresa sucroalcooleira nele instalada. Vale salientar que o município onde a empresa desenvolve a atividade econômica apresentou um índice de desenvolvimento sustentável municipal em situação crítica, conforme Martins e Cândido (2008).

A Secretaria de Finanças e Desenvolvimento, por sua vez, alerta que a contribuição da Empresa para o município pode ser realizada por meio do desenvolvimento de Projetos nas áreas temáticas: Educação, Cultura e Proteção Ambiental.

A Secretaria de Saúde mostra preocupação com a qualidade de vida das pessoas da comunidade por meio dos empregos que possam estar sendo gerados pela empresa no município.

Um dos vereadores acredita que a empresa, estando fortalecida, encontra-se em condições de contribuir com a sustentabilidade do município; o Presidente da Associação dos Trabalhadores Rurais do Município mostrou preocupação com o desemprego gerado pela substituição do homem pela máquina na cultura canavieira. Esta é uma questão polêmica no setor sucroalcooleiro: se de um lado a queima da cana provoca impactos ambientais negativos, 
por outro lado o uso de máquinas na colheita da cana gera desemprego para a grande quantidade de trabalhadores que dependem dessa atividade.

A percepção da Competitividade da Empresa Base pelo Poder Público do Município foi averiguada na dimensão Ambiente Institucional, por meio da variável Tradições e Costumes, por ela encontrar-se diretamente ligada ao comportamento da comunidade local. Os indicadores adotados foram os mesmos utilizados para a avaliação da competitividade da Empresa Base para essa dimensão. Assim, permite-se que se faça triangulação de dados nessa dimensão de suma importância para a competitividade de sistemas agroindustriais. Dessa forma, os indicadores utilizados foram: percepção sobre a comunidade em relação a nível de confiança, interesse e espírito de participação, qualidade de vida; percepção em relação ao comportamento e às ações da comunidade e influência da empresa para melhoria da comunidade.

No que se refere à competitividade, constatou-se um índice positivo de $75 \%$ considerando-se todas as respostas dos agentes, ou seja, sem levar em consideração as dimensões de forma isolada. Porém, quando analisadas de forma isolada, observa-se que o Secretário de Educação avaliou a totalidade das variáveis apresentadas de forma positiva. No estudo da competitividade, no que diz respeito às relações de cooperações com a comunidade foram consideradas três dimensões, com os respectivos resultados e considerações:

A primeira aborda a percepção sobre a comunidade em relação ao nível de confiança, interesse e espírito de participação e qualidade de vida. Praticamente todos os agentes avaliaram positivamente estes indicadores. Apenas o indicador "interesse e espírito de participação" foi avaliado negativamente pelo Secretário de Saúde.

$\mathrm{Na}$ segunda dimensão, "Percepção em relação ao comportamento e ações da comunidade" foi observado um consenso na variável "as relações entre as pessoas são geralmente harmoniosas". Outras duas variáveis destacaram-se com índices positivos de 80\%: "A maioria das pessoas são honestas e confiáveis" e "As pessoas contribuem (tempo e dinheiro) para desenvolvimento local", ou seja, apenas o representante do Poder Executivo (Vereador) expressou opinião contrária.

A terceira e última dimensão estudada apresentou um comportamento adverso. A influência da empresa e a contribuição para melhoria de vida das pessoas na comunidade foi consenso entre os agentes, enquanto apenas um agente (Secretário de Educação) concordou com a influência do governo local.

A avaliação da contribuição do setor sucroalcooleiro para o desenvolvimento do município foi positiva para todos os agentes entrevistados.

\subsection{Percepção de representante do órgão SUDEMA}

Os questionamentos feitos à SUDEMA tiveram por propósito averiguar a sua percepção acerca da conduta e performance ambientais das empresas do setor sucroalcooleiro paraibano como forma de melhor compreender a conduta e performance ambientais da empresa base e assim verificar as possíveis relações entre as variáveis desse estudo, quais sejam: estratégia ambiental, competitividade e sustentabilidade. Também foram feitos questionamentos acerca de como as empresas do setor sucroalcooleiro podem contribuir para a sustentabilidade de um município. A Tabela 2 e o Quadro 4 detalham os resultados obtidos na pesquisa de campo. 
Tabela 2- Percepção da SUDEMA acerca da Conduta Ambiental das Empresas do Setor Sucroalcooleiro da Paraíba.

\begin{tabular}{|c|c|c|}
\hline Indicadores & Avaliação & Peso \\
\hline 1. Pessoa responsável pelo gerenciamento ambiental & Fraca & $-1,0$ \\
\hline 2. Importância das questões ambientais para a direção das empresas & Forte & 1,0 \\
\hline 3. As empresas possuem uma política ambiental escrita. & Fraca & $-1,0$ \\
\hline $\begin{array}{l}\text { 4. As empresas conhecem a Legislação Ambiental relativa às suas } \\
\text { atividades }\end{array}$ & Forte & 1,0 \\
\hline 5. Como é realizado o acompanhamento da Legislação Ambiental. & Intermediária & 0,0 \\
\hline $\begin{array}{l}\text { 6. Foram realizados investimentos para o andamento da Legislação } \\
\text { Ambiental. }\end{array}$ & Intermediária & 0,0 \\
\hline $\begin{array}{l}\text { 7. As empresas já sofreram alguma multa/notificação do órgão de } \\
\text { fiscalização ambiental nos últimos dois anos. Quantificar. }\end{array}$ & Fraca & -1 \\
\hline 8. Existe um programa de educação ambiental nas empresas. & Intermediária & 0 \\
\hline 9. Os produtos fabricados pela empresa possuem selo verde. & Fraca & -1 \\
\hline $\begin{array}{l}\text { 10. As empresas aplicam algum padrão mínimo de exigência ambiental } \\
\text { aos seus parceiros de negócios. Se a resposta for não, passe para a } \\
\text { questão } 17 \text {. }\end{array}$ & Fraca & -1 \\
\hline $\begin{array}{l}\text { 11. As empresas estão implementando um Sistema de Gestão } \\
\text { Ambiental. }\end{array}$ & Fraca & -1 \\
\hline 12. As empresas estabelecem indicadores de performance ambiental. & Intermediária & 0 \\
\hline $\begin{array}{l}\text { 13. Como são tratadas as reclamações/sugestões das partes } \\
\text { interessadas (cliente, comunidade, organizações governamentais e } \\
\text { não governamentais, acionistas, financiadores). }\end{array}$ & Intermediária & 0 \\
\hline $\begin{array}{l}\text { 14. As empresas produzem relatórios apresentando a performance } \\
\text { ambiental. }\end{array}$ & Intermediária & 0,0 \\
\hline $\begin{array}{l}\text { 15. Forma de cooperação entre a SUDEMA e as empresas no trato das } \\
\text { questões ambientais }\end{array}$ & Forte & 1,0 \\
\hline $\begin{array}{l}\text { 16. Percepções de benefícios diretos ou indiretos das ações de gestão } \\
\text { ambiental desenvolvidas pelas empresas. }\end{array}$ & Fraca & $-1,0$ \\
\hline $\begin{array}{l}\text { 17. Você conhece a estratégia ambiental das empresas do setor } \\
\text { sucroalcooleiro. }\end{array}$ & Fraca & $-1,0$ \\
\hline SOMA & & $-2,0$ \\
\hline MÉDIA & & $-0,3$ \\
\hline
\end{tabular}

Fonte: Pesquisa Direta (2009).

Quadro 4: Percepção de representante da SUDEMA acerca da Performance Ambiental das Empresas do Setor Sucroalcooleiro da Paraíba

\begin{tabular}{|l|l|l|}
\hline INDICADORES & \multicolumn{1}{|c|}{ RESPOSTAS } & \multicolumn{1}{c|}{ AVALIAÇÃo } \\
\hline $\begin{array}{l}\text { 1. Quais os principais impactos } \\
\text { ambientais das atividades, } \\
\text { produtos ou serviços das } \\
\text { empresas. Estabelecer um } \\
\text { ranking de prioridade. }\end{array}$ & $\begin{array}{l}\text { Efeito estufa, contaminação do } \\
\text { solo Carga orgânica do efluente } \\
\text { líquido. (Se a vinhaça não for } \\
\text { bem tratada). }\end{array}$ & $\begin{array}{l}\text { A variável não é passível de } \\
\text { análise }\end{array}$ \\
\hline $\begin{array}{l}\text { 2. Quais são os indicadores de } \\
\text { performance ambiental } \\
\text { estabelecidos pelas }\end{array}$ & $\begin{array}{l}\text { Água, Efluentes líquidos, } \\
\text { Resíduos Sólidos, Ruído. }\end{array}$ & $\begin{array}{l}\text { A variável não é passível de } \\
\text { análise }\end{array}$ \\
\hline
\end{tabular}


empresas.

Fonte: Pesquisa Direta (2010).

A percepção de representante da SUDEMA em relação à conduta ambiental das empresas do setor sucroalcooleiro paraibano, assim como o resultado da conduta ambiental da Empresa Base, apresentou também uma tendência a uma conduta intermediária, porém, neste caso obteve-se um resultado negativo, o que aproxima a situação dessas empresas de uma conduta fraca.

Em relação aos elementos necessários para que uma empresa contribua com a sustentabilidade de um município, a SUDEMA se diz satisfeita com a adequação à legislação ambiental por parte dessas empresas.

\subsection{Percepção do presidente do SINDALCOOL}

A entrevista com o representante do SINDALCOOL ocorreu de forma não estruturada. Alguns questionamentos relativos às variáveis da pesquisa foram levantados; a partir disso, o mesmo se posicionava, e outros pontos foram abordados por iniciativa do entrevistado. 0 conteúdo da entrevista pode ser apreciado como descrito a seguir.

Em relação aos parceiros do Sindicato, o entrevistado apontou: as 9 empresas sucroalcooleiras do estado da Paraíba; Universidade Federal da Paraíba (UFPB); Universidade Federal de Pernambuco (UFPE); Rede Interuniversitária para o desenvolvimento do Setor Sucroalcooleiro (RIDESA); Financiadora de Estudos e Projetos (FINEP); Cetrel; Associação para proteção da Mata Atlântica do Nordeste (AMANE); Centro de Pesquisas Ambientais do Nordeste (CEPAN).

No que se refere à sustentabilidade, o entrevistado falou da importância do setor levar em consideração as dimensões econômica, social e ambiental, entretanto, em sua opinião, a sustentabilidade econômica é fundamental para dar apoio às outras dimensões. O entrevistado ainda ressaltou que 7 empresas sucroalcooleiras na Paraíba assinaram o compromisso nacional no sentido de manter clima de respeito, regulamentação de normas do trabalho rural e promover o rural alfabetizado. Em relação à variável ambiental, concorda que existem problemas: "a gente já gostaria de ter deixado de queimar a cana". Em seu entendimento, é preciso melhor aproveitar a cana por meio de caldeiras mais modernas (está em estudo a implantação de um Centro de Pesquisa em Restauração Florestal e Educação Ambiental). É um "diamante que espero polir nesse corredor ecológico", disse o entrevistado. Em relação aos conflitos no setor, observou que há conflitos de interesses. Em suas palavras "não há dúvidas que o conflito se estabelece quando uma das partes desrespeita o outro". Ressaltou ainda que o ano de 1991 transcorreu sem conflitos e que hoje o representante do sindicato é recebido na diretoria das empresas, mostrando que as relações entre o sindicato e as empresas melhoraram consideravelmente. Enfim, em suas palavras, vive-se um "período de modernidade".

Quanto ao compartilhamento de informações, o entrevistado afirmou que ele acontece em função de cada projeto. Chamou a atenção para o fato de que as estratégias coletivas precisam aperfeiçoar mecanismos que possam viabilizar compras coletivas, a exemplo de "Pools", o que iria beneficiar a todos. Frisou que outras ações que possam trazer ganhos para toda cadeia produtiva vão sendo buscadas dentro de cada projeto, sob a orientação do conselho, 
que traça a política mais ampla que é discutida pelas empresas. A respeito dos mecanismos de coordenação no setor, o entrevistado apontou que o mesmo se viabiliza por meio do Conselho dos Produtores de Cana-de-açúcar, Açúcar e Álcool (CONSECANA), responsável por definir o preço da cana-de-açúcar por meio de uma fórmula em função do mercado; em sua opinião, não é o ideal, mas é de comum acordo e vem sendo aperfeiçoado por meio de estudos. Observa que o preço de álcool e da cana mais alto remunera melhor o trabalhador, pois o preço não é feito aleatoriamente. Enfatizou que a Paraíba é o único estado do país que tem o cuidado de remunerar os trabalhadores baseando-se no preço final do produto.

A gestão ambiental das empresas do setor sucroalcooleiro na Paraíba, no que se refere à certificação ambiental, ainda é incipiente. Apenas uma empresa apresenta certificação ambiental na área agrícola; outras estão tentando alcançar. Conforme o entrevistado, a certificação EurepGap seria mais apropriada para agroindústrias, sendo já utilizada em 100 países. Na região sul se discute outra certificação.

No que se refere ao aspecto tecnológico, o entrevistado falou da importância das parcerias que devem ser estabelecidas entre o setor e as universidades para pesquisas que desenvolvam produtos com mais valor agregado. Segundo ele, as empresas precisam evoluir do estágio atual em que se encontram para melhor aproveitamento da biomassa e da sacarose; ele ainda alertou que "a solução dos nossos problemas tem que partir de nós mesmos". Percebe que a competitividade vem se reduzindo devido ao grande crescimento de outras regiões do país e aponta que o principal fator limitante da nossa competitividade são os custos de produção. Falou da importância de se considerar nas negociações a sustentabilidade social e ambiental, mas que isso tem um custo e muitas vezes a outra parte da negociação não está disposta a pagar esse custo, ou seja, às vezes não interessa para a outra parte como o produto foi produzido, pois o que interessa é o menor preço.

\section{CONSIDERAÇÕES FINAIS}

No que se refere à percepção de alguns stakeholders acerca das variáveis da pesquisa (estratégia ambiental, competitividade e sustentabilidade) podem ser feitas as conclusões seguintes.

Os atores sociais do Poder Público e da SUDEMA afirmaram não conhecer a estratégia ambiental da empresa; a Associação dos Trabalhadores Rurais do município afirmou conhecê-la e avaliou positivamente; para o presidente do SINDALCOOL, a gestão ambiental do setor sucroalcooleiro na Paraíba, no que concerne à certificação, ainda é incipiente.

Os elementos necessários à sustentabilidade do município foram percebidos de forma diferenciada pelos atores do Poder Público. $O$ ator social que respondeu a entrevista em nome da SUDEMA se diz satisfeito com a adequação à legislação ambiental por parte das empresas para garantir a sustentabilidade do município. Por sua vez, o presidente do SINDALCOOL afirmou que a sustentabilidade econômica é fundamental para dar apoio às dimensões social e ambiental.

Quanto à competitividade, foi questionado para o Poder Público a dimensão tradições e costumes com uma avaliação positiva. O presidente do SINDALCOOL percebe que a competitividade vem se reduzindo na Paraíba por conta do crescimento de outras regiões e aponta os custos de produção como o principal fator limitante. 
Constatou-se que os stakeholders percebem de forma diferenciada a contribuição da estratégia ambiental para a sustentabilidade do município e competitividade da empresa. Apreende-se que a interação da empresa com stakeholders que impactam suas atividades possibilitará um fluxo de informações contínuo que poderá contribuir para uma estratégia ambiental inserida no contexto das demandas desses atores sociais com possibilidades de ganhos para o binômio competitividade/sustentabilidade.

A contribuição deste artigo está vinculada ao despertar de novas discussões e estudos acerca das relações que possam se estabelecer entre a contribuição da estratégia ambiental para a competitividade de uma empresa, ao tempo em que contribui para a sustentabilidade do município em que está inserida.

As limitações do artigo dizem respeito, principalmente, ao número reduzido de stakeholders que foram entrevistados para este estudo de caso. Sugere-se que este trabalho seja observado em outros sistemas agroindustriais e com um número mais expressivo de stakahloders.

\section{REFERÊNCIAS}

1. ALTKINSON, Anthony A.; WATERHOUSE, John.A stakeholders approach to strategic performance measurement.Sloan Management Review, v.38, n.3, p. 25-36, spring 1997.

2. ANDREWS, Kenneth. The concept of corporate strategy. In: QUINN, J. B. ; MINTZBERG, H. \& JAMES, R. M. The strategy process: concepts, contex and cases. Englewoodcliffs, New Jersey: Prentece Hall, 1998. cap. 1, p. 1 - 17.

3. BARBOSA, Maria de Fátima Nóbrega. Práticas ambientais, competitividade e sustentabilidade: um estudo exploratório em empresa do setor sucrolacooleiro no município de Pedras de Fogo - PB. 2010. 261f. Tese (Doutorado em Recursos Naturais) - Universidade Federal de Campina Grande, Campina Grande/PB, 2010.

4. BOSSEL, Hartmut. Earth at a crossroads: paths to a sustainable future. Cambridge: Cambridge University Press, 1998.

5. BROWN, Lester Russel. Eco-Economia: construindo uma economia para a terra. Salvador: UMA, 2003.

6. CAPRA, Fritjof. O ponto de mutação. Tradução de: Álvaro Cabral. São Paulo: Cultrix, 1982.

7. DEL RIO, Vicente; OLIVEIRA, Lívia de (Orgs.). Percepção ambiental: a experiência brasileira. São Carlos, SP: Editora da UFSCar, 1999.

8. DONALDSON, Thomas; PRESTON, Lee. The stakeholder theory of the corporation: concepts, evidence and implications. Academy of Management Review., v. 20, p. 65-91, jan, 1995.

9. EGRI, Carolyn P.; PINFIELD, Laerence, T. As Organizações e a Biosfera: ecologia e meioambiente. In: CLEGG, Stewart, R.; HARDY, Cynthia; NORD, Walter R. (Org.) Handbook de estudos organizacionais: modelos de análise e novas questões em estudos organizacionais. São Paulo: Atlas, 2007. cap. 14, p. 361-397.

10. FAgGIONATO, Sandra. Percepção ambiental. Disponível em < http://educar.sc.usp. $\mathrm{br} /$ biologia/textos/m_a_txt4.html>. Acesso em 10 de maio de 2013. 
11. FARINA, Elizabeth Maria Mercier Querido. Competitividade e coordenação de sistemas agroindustriais: um ensaio conceitual. Gestão\&Produção, v. 6, n. 3, p. 147-161, 1999.

12. FERRARA, Lucrecia D'Alessio. Olhar periférico: informação, linguagem e percepção ambiental. São Paulo: Editora da Universidade de São Paulo: 1993.

13. FERREIRA, Aurélio Buarque de Holanda. Novo Aurélio século XXI: dicionário da língua portuguesa. Rio de Janeiro: Nova Fronteira, 1999.

14. FREEMAN, Edward R. Strategic Management: a stakeholder approach. London: Pitman Publishing, 1984.

15. HAMEL, Gary. Strategy as revolution. Harvard Business Review. Jul./Aug. 1996.

16. HARDI, Peter.; ZDAN, Terrence. J. Assessing sustainable development: principles in practice. Winnipeg: IISD, 1997.

17. HENDERSON, Bruce. The origin of strategy.Harvard Business Review. Nov./Dec. 1989.

18. JONES, Thomas M. Instrumental stakeholders theory: a synthesis of the ethics and economics. Academyof Management Review.,v. 20, p. 404-437, jan, 1995.

19. KEY, John. Fundamentos do sucesso empresarial: como as estratégias de negócios agregam valor. Rio de Janeiro: Campus, 1996.

20. LEFF, Enrique. Epistemologia ambiental. 2. ed. São Paulo: Cortez, 2002.

21. MARTINS, Maria de Fátima; CÂNDIDO, Gesinaldo Ataíde. İndice de Desenvolvimento Sustentável para Municípios (IDSM): metodologia para cálculo e análise do IDSM e classificação dos níveis de sustentabilidade para espaços geográficos. João Pessoa: SEBRAE, 2008.

22. METCALFE, Chris E. The Stakeholder Corporation.Business Ethics, v. 7, n.1, Jan. 1998.

23. MINTZBERG, Henry; LAMPEL, Joseph; AHLSTRAND, Bruce. Todas as partes do elefante. In: JÚLIO, Carlos Alberto; SALIBI NETO, José. Estratégia e planejamento: autores e conceitos imprescindíveis. São Paulo: Publifolha, 2002. cap. 1, p. 8-20.

24. MITCHELL, Ronald.; AGLE, Bradley.; WOOD, Donna. "Toward a theory of stakeholder identification and salience: defining the principle of who and what really counts". Academy of Management Review, v. 22, n. 4, p. 853-858.

25. MOORE, Geoff. Tinged shareholders theory: or what's so special about stakeholders? Business Ethics: A European Review, v.8, n. 2, 1999.

26. NILSSON, W. R. Services instead of products: experiences from energy markets - examples from Sweden. In: MEYER - KRAHMER, F. (Ed.). Innovation and sustainable development: lessons for innovation policies. Heidelberg: Physica - Verlag, 1998. p. 115-141.

27. PORTER, M. What is strategy? Harvard Business Review. nov./dec. 1996.

28. QUINN, J. B. Strategy for change. In: QUINN, J. B. ; MINTZBERG, H.; JAMES, R. M. The strategy process: concepts, context and cases. Englewood Cliffs, New Jersey: Prentice Hall, 1998. $998 \mathrm{p}$.

29. RIBEIRO, L.M. O papel das representações sociais na educação ambiental. 2003. Dissertação (Mestrado em Educação) - Pontifícia Universidade Católica, Rio de Janeiro/RJ, 2003.

30. RUTHERFORD, lan. Use of models to link indicators of sustainable development. In: MOLDAN, 
B.; BILHARZ, S. Sustainability indicators: report of the project on indicators of sustainable development. Chichester: John Wiley\& Sons Ltd, 1997. p. 47-54.

31. SACHS, Ignacy. Desenvolvimento sustentável, bio-industrialização descentralizada e novas configurações rural-urbanas: os casos da Índia e do Brasil. In: VIEIRA, Paulo Freire e WEBER, Jacques (Orgs.). Gestão de recursos naturais renováveis e desevolvimento: novos desafios para a pesquisa ambiental. São Paulo: Cortez, 1997. cap. 15, p. 469-494.

32. SHANKMAN, Neil A. Reframing the debate between agency and stakeholders theories of the firm. Journalof Business Ethics, v. 21, n. 4, 1999.

33. SILVA, Carlos Arthur B. da; BATALHA, Mário Otávio. Competitividade em sistemas agroindustriais: metodologia e estudo de caso. In: 2. WORKSHOP BRASILEIRO DE GESTÃO DE SISTEMAS AGROALIMENTARES. Ribeirão Preto: PENSA/FEA/USP, 1999.

34. TUAN, Yi-Fu. Topofilia: um estudo da percepção e valores do meio ambiente. São Paulo: Difel, 1980.

35. VASCONCELOS, Maria José Esteves de. Pensamento sistêmico: o novo paradigma da ciência. 3. ed. Campinas: Papirus, 2002.

36. VIEIRA, Paulo Freire. Ecodesenvolvimento: do conceito à ação. In: SACHS, Ignacy. Rumo à ecossocioeconomia: teoria e prática do desenvolvimento. São Paulo: Cortez, 2007. p. 10-31

37. WHETTEN, David. "What constitutes a theoretical contribution?"Academy of Management Review, v. 14, n. 1, p 490-495.

38. YIN, Robert K. Estudo de Caso: planejamento e métodos. 3. ed. Porto Alegre: Bookman, 2005. 